\title{
On the potential of sub-mm passive MW observations from geostationary satellites to retrieve heavy precipitation over the Mediterranean Area
}

\author{
S. Pinori, F. Baordo, C. M. Medaglia, A. Mugnai, and B. Bizzarri \\ Consiglio Nazionale delle Ricerche - Istituto di Fisica dell'Atmosfera e del Clima, Area di Ricerca di Tor Vergata, Via Fosso \\ del Cavaliere 100, 00133 Roma, Italy
}

Received: 26 October 2005 - Revised: 15 September 2006 - Accepted: 20 September 2006 - Published: 29 November 2006

\begin{abstract}
The general interest in the potential use of the $\mathrm{mm}$ and sub-mm frequencies up to $425 \mathrm{GHz}$ resolution from geostationary orbit is increasing due to the fact that the frequent time sampling and the comparable spatial resolution relative to the "classical" $(\leq 89 \mathrm{GHz})$ microwave frequencies would allow the monitoring of precipitating intense events for the assimilation of rain in now-casting weather prediction models.

In this paper, we use the simulation of a heavy precipitating event in front of the coast of Crete island (Greece) performed by the University of Wisconsin - Non-hydrostatic Modeling System (UW-NMS) cloud resolving model in conjunction with a 3D-adjusted plane parallel radiative transfer model to simulate the upwelling brightness temperatures (TB's) at $\mathrm{mm}$ and sub-mm frequencies. To study the potential use of high frequencies, we first analyze the relationships of the simulated TB's with the microphysical properties of the UW-NMS simulated precipitating clouds, and then explore the capability of a Bayesian algorithm for the retrieval of surface rain rate, rain and ice water paths at such frequencies.
\end{abstract}

\section{Introduction}

Observation and measure of precipitation from space is important not only from a climatological point of view, but it has also a social impact, allowing the monitoring and forecasting of heavy rainfall events and flash floods in remote and mountain regions, where radar and rain gauges can detect and measure the precipitating rain only sparsely.

Microwave radiometric observations from low Earth orbit satellites are currently used to retrieve precipitation from space. This allows a good spatial resolution for the traditional microwave frequencies $(\leq 89 \mathrm{GHz})$ but a very coarse temporal resolution, with less than two overpasses per day

Correspondence to: S. Pinori

(s.pinori@isac.cnr.it) (per satellite) on the same area - which turns out to be a strong limitation for the observation of flash flood and heavy rain events that are characterized by short and intense precipitation pulses. On the other hand, the use of millimeter and sub-mm frequencies (below $450 \mathrm{GHz}$ ) on geostationary satellites would allow a continuous observation of the events with a spatial resolution comparable with the lower frequencies at present on orbit on polar satellites. The NASA-NOAA Geosynchronous Microwave Sounder Working Group developed the project of a sub-mm radiometer (GEosynchronous Microwave sounder and imager, GEM), equipped with a $2 \mathrm{~m}$ scanning antenna and channels in the oxygen $\left(\mathrm{O}_{2}\right)$ bands $(54$, 118 and $425 \mathrm{GHz}$ ) and in the water vapor (WV) lines (183 and 340/380 GHz), as listed in Table 1 (Staelin et al., 1998). In Europe a project specifically devoted to rain studies was proposed in 2001 to the European Community by Bizzarri et al., 2002, and more recently to ESA (Geostationary Observatory for Microwave Atmospheric Sounding, GOMAS). Clear-air Incremental Weighting Functions (IWFs) for temperature and humidity in the bands listed in Table 1 are presented in Fig. 1. The numbers attached to the curves indicate the offset (in MHz) from the associated line centre (from Klein and Gasiewski, 2000).

The GEM/GOMAS brightness temperatures at high frequencies have been simulated by using a cloud resolving model simulation of a heavy precipitation event over the south Mediterranean Sea, occurred close to Greece coasts and Crete island in November 2004 and causing several civil damages and injuries.

\section{Method and models}

The University of Wisconsin - Non-hydrostatic Modeling System (UW-NMS) Cloud Resolving Model (CRM) is used in conjunction with a 3-D-adjusted plane parallel radiative transfer model to investigate the potentiality of the $\mathrm{mm}$ and sub-mm frequency channels simulating the upwelling brightness temperatures (TB's) at $\mathrm{mm}$ and sub-mm frequencies. 

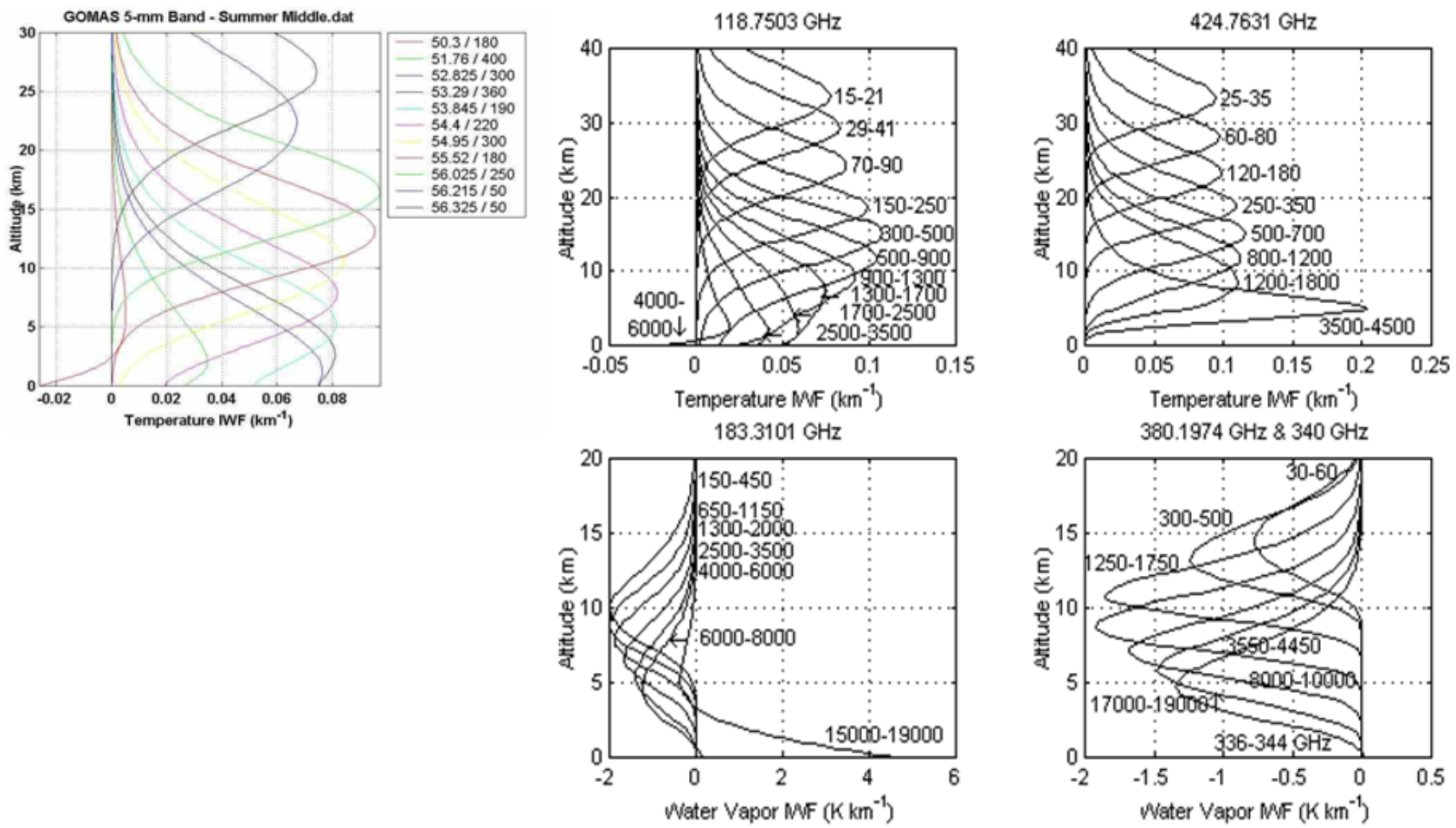

Fig. 1. Clear-air Incremental Weighting Functions (IWFs) for temperature and humidity in the bands listed in Table 1 (from Klein and Gasiewski, 2000). The numbers attached to the curves indicate the offset (in $\mathrm{MHz}$ ) from the associated line centre.

Table 1. GEM/GOMAS channel frequencies (dual-side channels) and bandwidth.

\begin{tabular}{|c|c|c|c|c|c|c|c|c|c|}
\hline $\begin{array}{c}54 \mathrm{GHz} \\
v \\
(\mathrm{GHz})\end{array}$ & $\begin{array}{c}\Delta v \\
(\mathrm{MHz})\end{array}$ & $\begin{array}{c}118 \mathrm{GHz} \\
v \\
(\mathrm{GHz})\end{array}$ & $\begin{array}{c}\Delta v \\
(\mathrm{MHz})\end{array}$ & $\begin{array}{c}183 \mathrm{GHz} \\
v \\
(\mathrm{GHz})\end{array}$ & $\begin{array}{c}\Delta v \\
(\mathrm{MHz})\end{array}$ & $\begin{array}{c}380 \mathrm{GHz} \\
v \\
(\mathrm{GHz})\end{array}$ & $\begin{array}{c}\Delta v \\
(\mathrm{MHz})\end{array}$ & $\begin{array}{c}425 \mathrm{GHz} \\
v \\
(\mathrm{GHz})\end{array}$ & $\begin{array}{c}\Delta v \mathrm{X} \\
(\mathrm{GHz})\end{array}$ \\
\hline 56.325 & 50 & $118.7503 \pm 0.018$ & 6 & $183.3101 \pm 0.300$ & 300 & $380.1974 \pm 0.045$ & 30 & $424.7631 \pm 0.030$ & 10 \\
\hline 56.215 & 50 & $118.7503 \pm 0.035$ & 12 & $183.3101 \pm 0.900$ & 500 & $380.1974 \pm 0.400$ & 200 & $424.7631 \pm 0.070$ & 20 \\
\hline 56.025 & 250 & $118.7503 \pm 0.080$ & 20 & $183.3101 \pm 1.650$ & 700 & $380.1974 \pm 1.500$ & 500 & $424.7631 \pm 0.150$ & 60 \\
\hline 55.520 & 180 & $118.7503 \pm 0.200$ & 100 & $183.3101 \pm 3.000$ & 1000 & $380.1974 \pm 4.000$ & 900 & $424.7631 \pm 0.300$ & 100 \\
\hline 54.950 & 300 & $118.7503 \pm 0.400$ & 200 & $183.3101 \pm 5.000$ & 2000 & $380.1974 \pm 9.000$ & 2000 & $424.7631 \pm 0.600$ & 200 \\
\hline 54.400 & 220 & $118.7503 \pm 0.700$ & 400 & $183.3101 \pm 7.000$ & 2000 & $380.1974 \pm 18.000$ & 2000 & $424.7631 \pm 1.000$ & 400 \\
\hline 53.845 & 190 & $118.7503 \pm 1.100$ & 400 & $183.3101 \pm 17.000$ & 4000 & 340.0 & 8000 & $424.7631 \pm 1.500$ & 600 \\
\hline 53.290 & 360 & $118.7503 \pm 1.500$ & 400 & & & optional/auxiliary & & $424.7631 \pm 4.000$ & 1000 \\
\hline 52.825 & 300 & $118.7503 \pm 2.100$ & 800 & & & & & & \\
\hline 51.760 & 400 & $118.7503 \pm 3.000$ & 1000 & & & & & & \\
\hline 50.300 & 180 & $118.7503 \pm 5.000$ & 2000 & & & & & & \\
\hline
\end{tabular}

We used then a Bayesian algorithm (BAMPR - Bayesian Algorithm for Microwave Precipitation Retrieval) for the retrieval of the precipitation rate, and rain/ice water paths at such frequencies.

\subsection{Cloud resolving model}

The CRM uses a three-dimensional time-dependent explicit non-hydrostatic scheme, developed at the University of Wisconsin, (UW-NMS - Non-hydrostatic Modeling System, Tripoli 1992). The UW-NMS generalized bulk microphysics scheme predicts the mixing ratios of six different hydrometeors (cloud droplets, rain drops, graupel particles, pristine ice crystals, snow, and ice aggregates). All particles are assumed to be spherical. While cloud droplets and pristine ice crystals are assumed to be monodispersed (with characteristic diameters of 20 and $240 \mu \mathrm{m}$, respectively), the other hydrometeors are supposed to be distributed with size (diameter $D$ ), according to inverse-exponential constantslope/constant-intercept size distributions (Panegrossi et al., 1998):

$N(D)=A e^{-B D}$ 
where the intercept $(A)$ or the slope $(B)$, the two parameters that describe the Marshall-Palmer drop size distribution, are derived by the model at each grid point. Finally, it is assumed that ice crystals, graupel particles, and snowflakes have constant density $(\rho)$ equal to $0.1 \mathrm{~g} / \mathrm{cm}^{3}, 0.9 \mathrm{~g} / \mathrm{cm}^{3}$, and $0.2 \mathrm{~g} / \mathrm{cm}^{3}$, respectively, while ice aggregates have sizedependent densities $\rho=0.015 / D^{0.6} \mathrm{~g} / \mathrm{cm}^{3}$.

Several factors can contribute to the uncertainties induced by the assumptions in the CRM and in the RTM: the size spectra of the hydrometeors, the high-density graupel, sea surface wind speed, the temperature profiles, the particles shape, the radiative transfer approximations, and the antenna beamwidth. In Tassa et al. (2006) an estimate of the modelling uncertainties using a Bayesian precipitation retrieval for passive microwave data at the TRMM/TMI frequencies $(10,19,37,85 \mathrm{GHz})$ is presented. In this paper has been shown that ice particles modelling uncertainties play a dominant role at the highest frequencies ( 37 and $85 \mathrm{GHz}$ ) and we should expect that a similar behavior could be also valid for the sub-mm frequencies (mainly sensitive to the iced particles, as snow and graupel) used to retrieve precipitation in this paper. Even if the hydrometeor parameterization is not able to reproduce the real particles distribution inside the cloud (but uses a schematic representation that simplify the reality), we can assume that this model satisfies our purpose of simulating sub-mm passive microwave satellite observations.

The simulation of the south Mediterranean Sea on 4-5 November 2004 event has a horizontal spatial resolution of $6.0 \mathrm{~km}$, with 29 vertical levels having a height-dependent spacing. The event occurred west of Crete island (Greece) and produced high precipitation rates on the coast of the island and giving a cumulated rainfall of $250 \mathrm{~mm}$ on the sea in front of the Crete coasts (see Fig. 2). The minute selected for this study correspond to the situation at 12:00 UTC of the 4 November 2004, when very intense convective cells are located over the Central Mediterranean sea between Sicily island and the Greek coasts with peaks of rainfall rate at $\sim 60 \mathrm{~mm} / \mathrm{h}$ and a low pressure system located south of the Sicily island (Italy) with a minimum of $1008 \mathrm{mb}$. Figure 4 shows the columnar liquid/ice water content for rain, snow and graupel at the selected minute.

\subsection{Radiative transfer model}

The Radiative Transfer Model (RTM) converts the simulated precipitation event into a pattern of upwelling brightness temperatures (TBs) at the specified frequencies. We use a 3-D-adjusted plane-parallel code developed by Roberti et al. (1994), Liu et al. (1996) and Bauer et al. (1998). The TB's are computed at model resolution $(6 \mathrm{~km})$. We take the customary assumption that all particles are spherical and homogeneous so that Mie theory can be applied for the determination of the single-scattering properties of the various hydrometeor species.

One of the major problems in the radiative transfer model at high frequencies is to reproduce brightness temperature
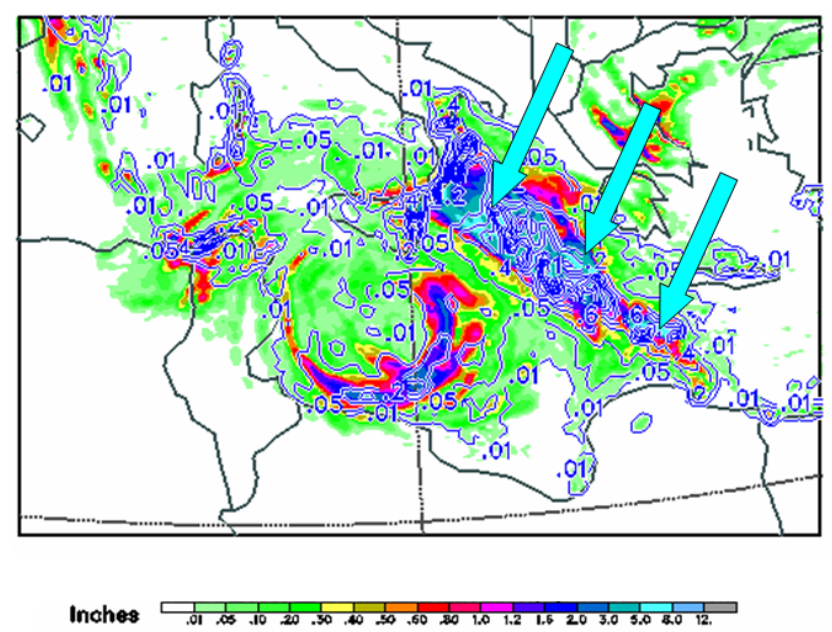

Fig. 2. Cumulated precipitation from 00:00 UTC of 4 November 2004 to 00:00 UTC of 6 November. The cyan areas (pointed out by the arrows) correspond to the high-raining cells with $250 \mathrm{~mm}$ (i.e. $\sim 10$ inches; 1 inch $=2.54 \mathrm{~cm}$ ) of cumulated rainfall.

consistent with those observed, because the scattering properties of the ice particles are not well modeled using the assumption that ice particles are spherical. Then, to compute the single-scattering properties of snow and aggregates we used the procedure of Grenfell and Warren (1999), who show that the scattering properties of non-spherical ice particles across the ultraviolet, visible and infrared portions of the electromagnetic spectrum are well approximated by a collection of solid ice spheres having the same volume-to-surfacearea ratios as non-spherical particles (see also Neshyba et al., 2003).

\subsection{Precipitation retrieval algorithm}

The precipitation retrieval method - BAMPR - is characterized by a detailed description of the estimation uncertainties, a careful coupling of the forward and inverse problem and a quantitative evaluation of the representativeness of the cloud-radiation database (Mugnai et al., 2001; Di Michele et al., 2003, 2005). The solution profiles were derived by using an iterative Bayesian method based on weighting different database profiles according to the proximity of measured and modeled TB's and on a priori probabilities of occurrence of given profile structures. Surface rain rates are derived from the estimated hydrometeor profiles using fallout equations. In this work, the database has been built using all the pixels in the simulation, except those present in the cross-section selected.

\section{Results}

The first step in the analysis of the high frequencies performances is to study the relationships of the simulated TB's with the microphysical properties of the UW-NMS simulated precipitating clouds. Figure 3 shows the most signif- 

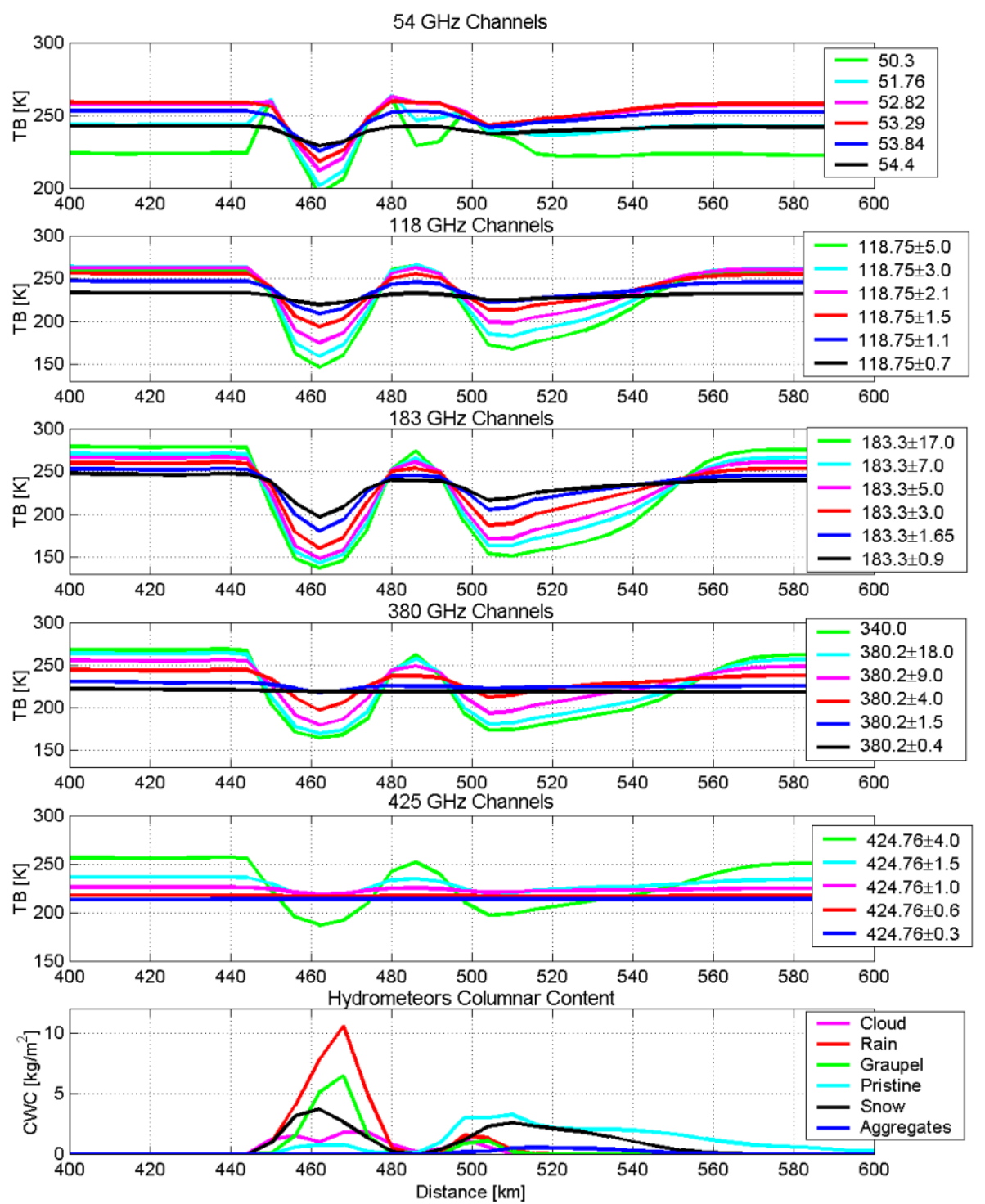

Fig. 3. TBs cross-sections for the most significant frequencies of GEM/GOMAS radiometer simulation. The bottom line represents the columnar water content of the six hydrometeors corresponding to the cross-section. The panels represent from top to bottom: $54,118,183$, $340 / 380$ and $425 \mathrm{GHZ}$ bands, respectively, and the bottom panel shows the columnar liquid/ice water content of the six hydrometeors used in the model and corresponding to the cross-section.

icant TBs cross-section of the GEM/GOMAS channels (Table 1) divided into bands. We can easily see that all the TBs show a steep decrease around $460 \mathrm{~km}$, due to the scattering of the high content of frozen hydrometeors (especially snow and graupel). Only the higher frequencies ( $\geq 118 \mathrm{GHZ}$ ) are sensitive to the very low content of the ice particles around $510 \mathrm{~km}$. If we consider the weighting functions of the different GOMAS channels (Fig. 1), we can see that only the 54 and $118 \mathrm{GHz}$ have channels sounding close to the ground $(<5 \mathrm{~km}$ ), whereas the other channels (the 118, 340/380 and the $425 \mathrm{GHz}$ ) are close to blind below height of $5 \mathrm{~km}$. This is reflected in cross-section of Fig. 3, where the sensitivity of the TBs at the different content hydrometeors decreases with increasing frequencies.
Second step has been to evaluate the performances of the retrieval of liquid and frozen hydrometeors. In Fig. 5 are presented the retrieved vertical profiles for rain and graupel corresponding to the cross-section outlined in Fig. 4, the mean verticals profiles computed as the average over the whole cross-section (the "true" profile, derived by the model in red and the retrieved profile in blue) with the associated error standard deviation. Three different sets of frequencies have been chosen to perform the retrieval: using only the $\mathrm{O}_{2}$ channels (54, 118 and 425 GHZ bands), using only the WV channels (183 and 340/380 GHz) and a combination of all the channels, respectively. We can see that the WV channel retrieval is the worst both in retrieving the frozen and the liquid precipitation. It presents an underestimation of the liquid and ice water content with the bigger standard deviation. On 

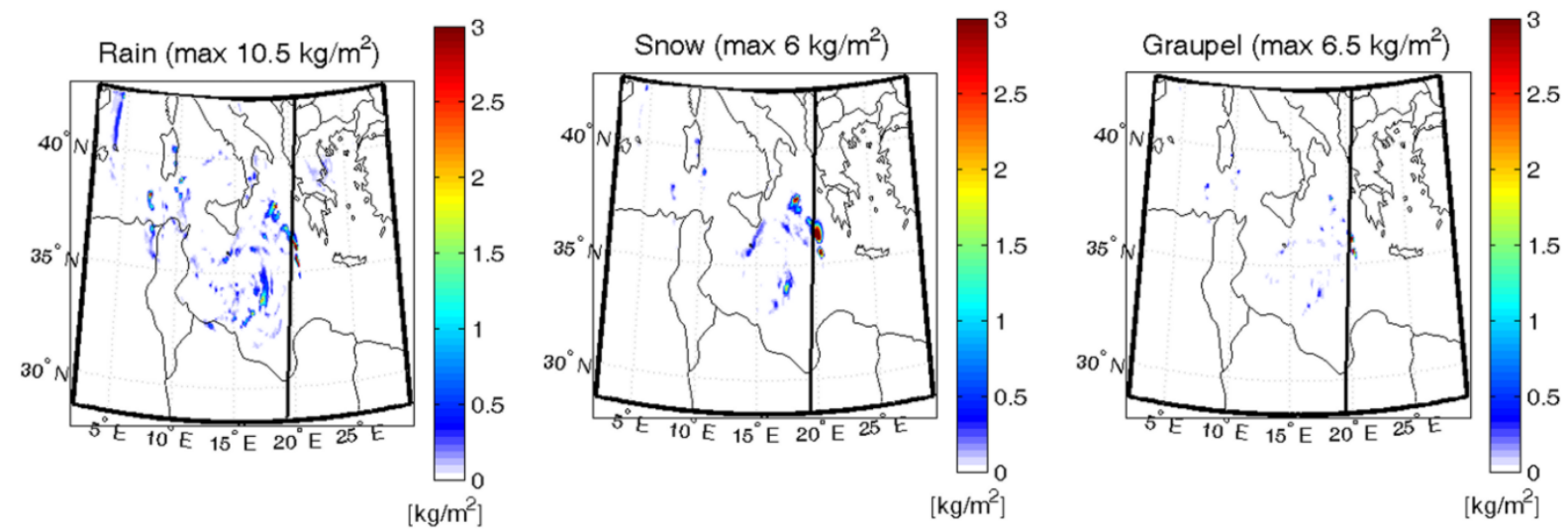

Fig. 4. Simulated columnar contents of rain, snow and graupel for the 4 November 2004 at 12:00 UTC. The black line indicates the crosssection used in the following analysis.
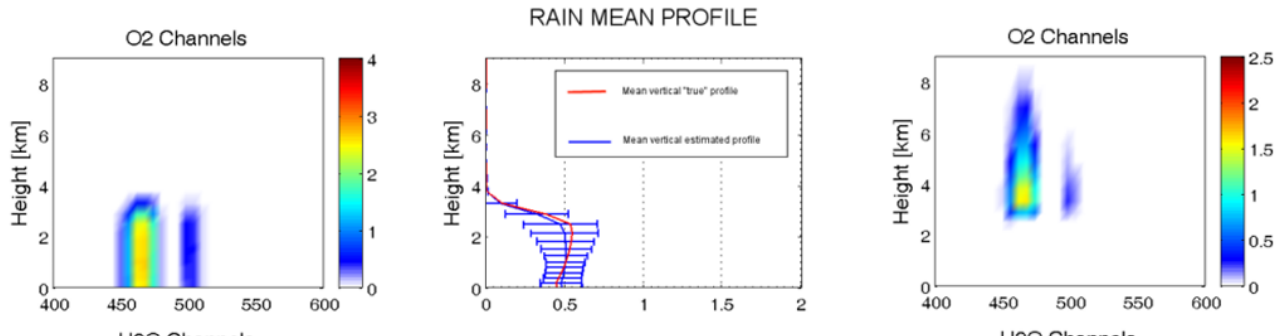

GRAUPEL MEAN PROFILE
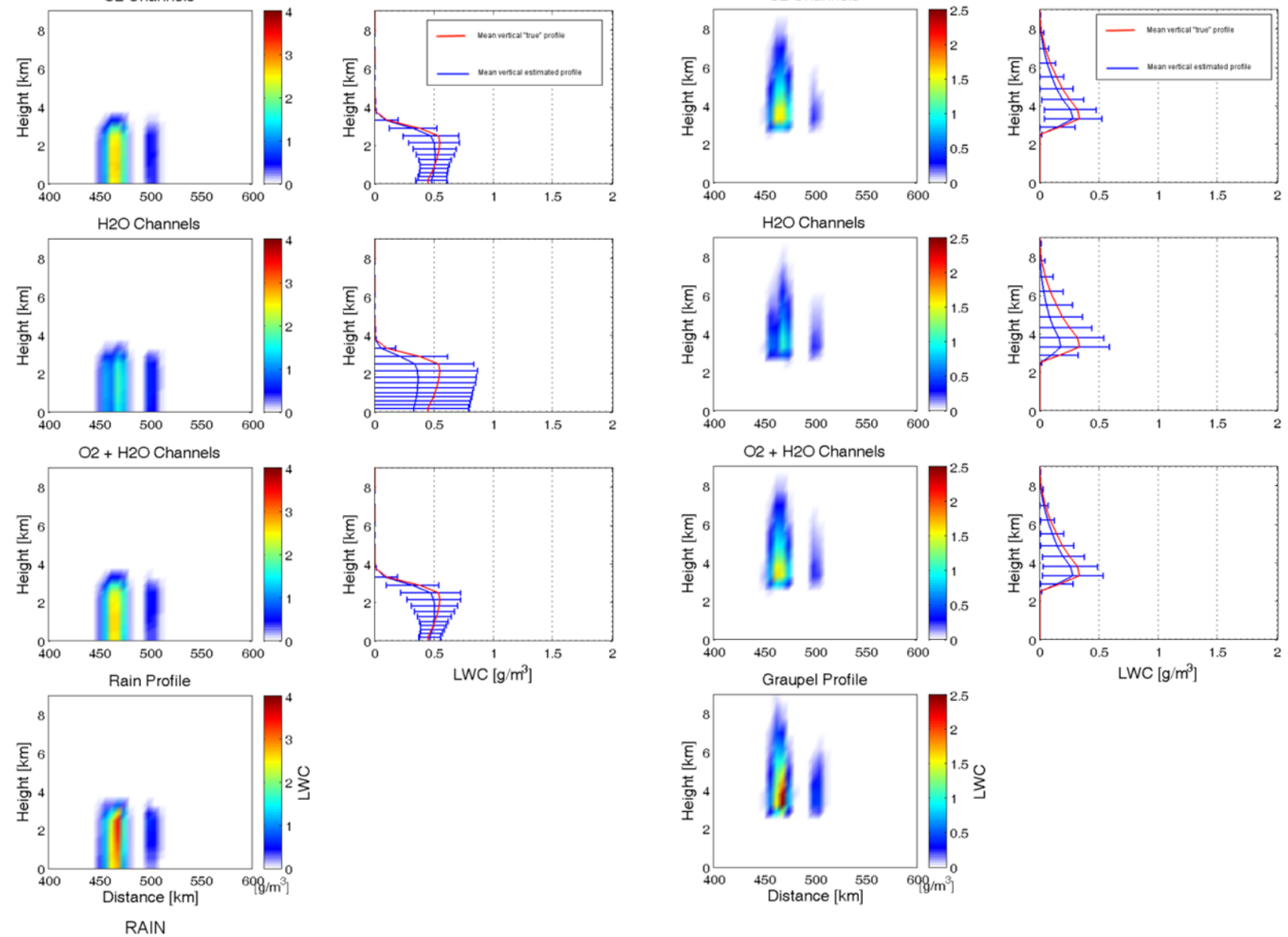

Fig. 5. Rain (left), and graupel (right) liquid/ice water content retrieval (first and third column). The bottom panels represent the CRM "truth" for each hydrometeor. The second and fourth columns represent the mean vertical "true" profile derived from the model (red) and the mean vertical estimated profile (blue) with the associated error standard deviation (the blue horizontal bars). The mean vertical profiles are the profiles ("true" or retrieved) averaged over the whole cross-section. 
Table 2. Correlation coefficient and root mean square (RMS) between the "truth" (model) and the retrieved water/ice water paths of the three hydrometeors (rain, graupel, and snow) and the rain rate for the three different sets of frequencies.

\begin{tabular}{lcccccccc}
\hline & \multicolumn{2}{c}{ RAIN } & \multicolumn{2}{c}{ GRAUPEL } & \multicolumn{2}{c}{ SNOW } & \multicolumn{2}{c}{ RAINRATE } \\
& Corr. & RMS & Corr. & RMS & Corr. & RMS & Corr. & RMS \\
\hline Only WV channels & 0.77 & 0.37 & 0.85 & 0.14 & 0.96 & 0.15 & 0.72 & 2.43 \\
Only $\mathrm{O}_{2}$ channels & 0.87 & 0.26 & 0.89 & 0.12 & 0.98 & 0.09 & 0.84 & 2.09 \\
All channels & 0.89 & 0.29 & 0.89 & 0.12 & 0.98 & 0.10 & 0.84 & 2.24 \\
\hline
\end{tabular}

Table 3. Contingency table of possible events.

\begin{tabular}{lllc}
\hline & \multicolumn{3}{c}{ RAIN MODEL } \\
& & $y$ & $n$ \\
\hline RAIN RETRIVED & $y$ & $y y$ & $y n$ \\
& $n$ & $n y$ & $n n$ \\
\hline
\end{tabular}

the contrary, the $\mathrm{O}_{2}$ channels retrieval give a better estimate of the vertical distribution of both the hydrometeors. For the rain water content retrieval the combination of all the channels presents the smallest standard deviation.

Next step was to quantify the goodness of the retrieval and to compare the performances of the different bands combinations, using several statistical parameters. The root mean square (RMS) and the correlation coefficient have been considered to analyze the behavior of the retrieval relative to the columnar liquid/ice water contents of rain, graupel, snow, and surface rain rate.

Table 2 presents the correlation coefficient and the RMS between rain, graupel, snow and surface rainfall rate for the three different bands combination described in Sect. 2.3 and the model "truth". We can see that the correlation coefficient of the retrieved quantities using only the WV channels is always the lowest (with values ranging from $72 \%$ for the rain rate to $96 \%$ for the snow retrieval). On the contrary, the performances of the $\mathrm{O}_{2}$ and the all-channels combinations are the same and very good (from $84 \%$ for the rain rate to $98 \%$ for the snow retrieval). Furthermore, the $\mathrm{O}_{2}$ bands show a smaller RMS relative to the all-channels combination. The contribution of $\mathrm{O}_{2}$-sounding bands to the retrieval of rain, graupel, snow and surface rain rate, is in all cases dominant with respect to the WV bands, and in fact nearly coincides with the performance of the full set of bands.

We have also to note that the rain rate has a very high correlation coefficient, even if the channels used are not directly related to the rain emission properties over ocean, but more to the scattering properties of the frozen particles.

A second set of statistical indexes have been employed to evaluate the rain detection capability, discriminating between the raining and non-raining pixels. To describe these indexes we have to introduce the so-called "contingency table" (Table 3), which provides the number of correctly and incorrectly classified pixels with respect to rain and no-rain regimes. Nomenclature is such that the "truth" is the CRM output and the "detected" is the retrieval product. A threshold value of $0.1 \mathrm{~mm} / \mathrm{h}$ for rainfall is selected to define rain areas for both simulated and retrieved rain fields.

To analyze the performances of the different band combinations (only $\mathrm{O}_{2}$ channels, only water vapor channels and using all the channels) we introduce the following statistical indexes (Jolliffe and Stephenson, 2002):

- Probability Of Detection (POD) - $y$ (if rain is retrieved both in the model output and in the retrieval), $n$ (if both the retrieval and the CRM do not consider the pixel as raining:

$$
\mathrm{POD} y=\frac{y y}{y y+n y}
$$

and

$$
\mathrm{POD} n=\frac{n n}{n n+y n}
$$

- False Alarm Rate (FAR) - it gives the percentage of the pixels in which there is no rain for the CRM and instead the retrieval detects rain:

$$
\mathrm{FAR}=\frac{n y}{y y+n y} \text {; }
$$

- BIAS - It represents the ratio of the number of "Yes" retrieved to the number of "Yes" in the model and is a measure of over- and under-estimate:

$$
\mathrm{BIAS}=\frac{y y+y n}{y y+n y}
$$

- Critical Success Index (CSI) - in some way, it is a combination of the previous two indexes, giving the number of pixels correctly estimated versus the number of the raining pixel both from model and retrieval:

$$
\mathrm{CSI}=\frac{y y}{y y+n y+y n} .
$$

The results of the statistical analysis computed over the entire model domain to determine the rain detection capability of the retrieval are presented in Tables 4 and 5. 
Table 4. Results in term of statistical analysis for the rain rate retrieval for the three different set of frequencies and the ideal value of each parameter.

\begin{tabular}{ccccc}
\hline & Only $\mathrm{O}_{2}$ channels & Only WV channels & All channels & Ideal value \\
\hline PODy & 0.64 & 0.70 & 0.64 & 1 \\
PODn & 0.98 & 0.97 & 0.99 & 1 \\
FAR & 0.20 & 0.38 & 0.18 & 0 \\
BIAS & 0.80 & 1.12 & 0.79 & $<1$ over-estimate \\
& & & & $=1$ no bias \\
& & & 0.56 & 1 under-estimate \\
CSI & 0.55 & 0.48 & 0.5 \\
\hline
\end{tabular}

Table 5. Results in term of statistical analysis for the three different set of frequencies and the ideal value of each parameter only for high precipitation pixels $(>10 \mathrm{~mm} / \mathrm{h})$.

\begin{tabular}{ccccc}
\hline & Only $_{2}$ channels & Only WV channels & All channels & Ideal value \\
\hline PODy & 0.56 & 0.36 & 0.56 & 1 \\
PODn & 0.99 & 0.99 & 0.99 & 1 \\
FAR & 0.15 & 0.25 & 0.12 & 0 \\
BIAS & 0.66 & 0.48 & 0.64 & $<1$ over-estimate \\
& & & & $=1$ no bias \\
& & & & \\
CSI & 0.51 & 0.36 & 0.51 & 1 \\
\hline
\end{tabular}

Table 4 presents the POD $y$, PODn, FAR, BIAS and CSI for the three different sets of frequencies. In terms of detection of surface rain, the WV bands have higher PODy than the temperature-sounding bands $(70 \%$ for the WV channels and $64 \%$ for the other two combinations). However, the FAR is the highest, being the double in this case (38\% instead of 18-20\% in the other two cases), so that the comprehensive CSI is finally much better for temperature-sounding bands than for the water vapour ones (with a score of 55-56\% and $48 \%$, respectively), close to that one of the full set of bands. Finally, the BIAS indicates that rainfall retrieved is underestimated for $\mathrm{O}_{2}$ and all-channels sets, while it is overestimated for the WV channels. If we consider the same statistical analysis for only high precipitating pixels $(>10 \mathrm{~mm} / \mathrm{h})$ presented in Table 5, we can see that the $\mathrm{O}_{2}$ and the all-channels combinations have the highest PODy and CSI (56\% and 51\%, respectively), having at the same time the lower FAR values $(12-15 \%)$. For the high precipitating pixels there is always the tendency of underestimate the values, but with larger discrepancies for the WV channels.

\section{Conclusions}

The previous analysis leads to the conclusion that the contribution of temperature-sounding bands to the retrieval of precipitation, is in all cases dominant with respect to the WV bands, and in fact nearly coincides with the performance of the full set of bands.
Therefore, the importance of the geostationary MW observation resides not only in the improved temporal sampling but also, as started to demonstrate within this work in the exploitation of the $\mathrm{O}_{2}$ bands for retrieving precipitation instead of using the $\mathrm{WV}$ bands, at present used onboard the operational MW satellite, because they show greater sensitivity and reliability to the vertical distribution of the hydrometeors and the retrieval of the rainfall rate. Future work will be to evaluate the impact of the real spatial resolution of each frequency, which will impact in particular on the lower frequencies.

Acknowledgements. The authors thank their colleagues for continuing support and discussion around the coffee breaks. This work is being carried out in the framework of EUMETSAT study contract EUM/CO/04/1386/KJG. We also thank G. J. Tripoli for the assistance with the UW-NMS model runs and E. Smith for the useful discussions about the retrieval method.

Edited by: V. Kotroni and K. Lagouvardos

Reviewed by: anonymous referee

\section{References}

Bauer P., Schanz, L., and Roberti, L.: Correction of the threedimensional effects for passive microwave remote sensing of convective clouds, J. Appl. Meteor., 37, 1619-1632, 1998.

Bizzarri, B., Amato, U., Bates, J., Benesch, W., Bühler, S., Capaldo, M., Cervino, M., Cuomo, V., De Leonibus, L., Desbois, M., Dietrich, S., Evans, F., Eymard, L., Gasiewski, A., Gustafsson, N., 
Heygster, G., Klein, M., Künzi, K., Levizzani, V., Liberti, G. L., Lopez-Baeza, E., Menzel, P., Miao, J., Mugnai, A., Pagano, P., Pailleux, J., Pardo, J., Porcù, F., Prigent, C., Prodi, F., Rizzi, R., Rochard, G., Roesli, H. P., Serio, C., Smith, W., Speranza, A., Staelin, D., Sutera, A., Tsou, J. J., Velden, C., and Visconti, G.: GOMAS - Geostationary Observatory for Microwave Atmospheric Sounding, submitted to ESA in response to the second call for proposals for ESA Earth Explorer Opportunity Missions, January 2002.

Di Michele, S., Marzano, F. S., Mugnai, A., Tassa, A., and Poiares Baptista, J. P. V.: Physically based statistical integration of TRMM microwave measurements for precipitation profiling, Radio Sci., 38(4), 8072, doi:10.1029/2002RS002636, 2003.

Di Michele, S., Tassa, A., Mugnai, A., Marzano, F. S., Bauer, P., and Poiares Baptista, J. P. V.: Bayesian algorithm for microwavebased precipitation retrieval: description and application to TMI measurements over ocean, IEEE Trans. Geosci. Rem. Sens., 43(4), 778-791, 2005.

Grenfell, T. C. and Warren, S. G.: Representation of a non-spherical ice particle by a collection of independent spheres for scattering and absorption of radiation, J. Geophys. Res., 104, $31697-$ 31709, 1999.

Jolliffe I. T. and Stephenson, D. B.: Forecast Verification, Wiley and Sons Ltd., 2002.

Klein, M. and Gasiewski, A. J.: The Sensitivity of Millimeter and Sub-millimeter Frequencies to Atmospheric Temperature and Water Vapor Variations, J. Geophys. Res.-Atmos., 13, $17481-$ $17511,2000$.

Liu, G., Simmer, C., and Ruprecht, E.: Three-dimensional radiative transfer effects of clouds in the microwave spectral range, J. Geophys. Res., 101, 4289-4298, 1996.
Mugnai, A., Di Michele, S., Marzano, F. S., and Tassa, A.: Cloud-model based Bayesian techniques for precipitation profile retrieval from TRMM microwave sensors, Proc. ECMWF/EuroTRMM Workshop on Assimilation of Clouds and Precipitation, ECMWF, Reading, UK, 323-345, 2001.

Neshyba, S. P., Grenfell, T. C., and Warren, S. G.: Representation of a non-spherical ice particle by a collection of independent spheres for scattering and absorption of radiation: 2. Hexagonal columns and plates, J. Geophys. Res., 108, 4448-4465, 2003.

Panegrossi, G., Dietrich, S., Marzano, F. S., Mugnai, A., Smith, E. A., Xiang, X., Tripoli, G. J., Wang, P. K., and Poiares Baptista, J. P. V.: Use of cloud model microphysics for passive microwavebased precipitation retrieval: Significance of consistency between model and measurement manifolds, J. Atmos. Sci., 55, 1644-1673, 1998.

Roberti, L., Haferman, J., and Kummerow, C.: Microwave radiative transfer through horizontally inhomogeneous precipitating clouds, J. Geophys. Res., 99, 16 707-16718, 1994.

Staelin, D. H., Gasiewsky, A. J., Kerekes, J. P., Shields, M. W., and Solman III, F. J.: Concept proposal for a GEostationary Microwave (GEM) Observatory, Prepared for the NASA/NOAA Advanced Geostationary Sensor (AGS) Program, MIT, Lexington Mass., USA, 23 pp., 1998.

Tassa, A., Di Michele, S., Mugnai, A., Marzano, F. S., Bauer, P., Poiares Baptista, J. P. V.: Modelling uncertainties for passive microwave precipitation retrieval: Evaluation of a case study, IEEE Trans. Geosci Remote Sens., 44(1), 78-89, 2006.

Tripoli, G. J.: A non-hydrostatic model designed to simulate scale interaction, Mon. Wea. Rev., 120, 1342-1359, 1992. 